\title{
PERSONAL FEAR OF DEATH AND GRIEF IN BEREAVED MOTHERS
}

\author{
PETER BARR \\ Royal Alexandra Hospital for Children, Sydney, Australia
}

JOANNE CACCIATORE

Arizona State University, Phoenix, Arizona, USA

\begin{abstract}
The study explored the relation of fear of death (Multidimensional Fear of Death Scale) to maternal grief (Perinatal Grief Scale-33) following miscarriage, stillbirth, neonatal death, or infant/child death. The 400 women participants were recruited from the website, $e$-mail lists, and parent groups of an organization that supports bereaved parents. Fear of death had a statistically significant relation with maternal grief. Fear of the Unknown, Fear of Premature Death, and Fear of Conscious Death made significant unique contributions to the variance in maternal grief. The fear of death operative in maternal grief seems to be the fear of personal extinction.
\end{abstract}

"We fear death - and that is why we reproduce after our kind"

(Kastenbaum, 1974, p. 63).

The fact that the death of a loved one should threaten selfhood and trigger personal death anxiety may seem self-evident on theoretical grounds (Raphael, 1983), but very little empirical research has focused on the relation of personal fear of death to grief (Bonanno et al., 2002). In particular, the untimely and unexpected death of a child should unravel the self (Furman, 1978) and void important

Received 10 November 2006; accepted 10 June 2007.

We are grateful to Professor Beverley Raphael and Professor Robert Kastenbaum for their comments on an earlier draft of this article and to Dr. Robert Halliday for automating the relative mean substitution method for inserting missing Likert scale values into SPSS. Address correspondence to Dr. Peter Barr, Department of Neonatology, The Children's Hospital at Westmead, Locked Bag 4001, Westmead, NSW, 2145, Australia. E-mail: peter@chw.edu.au 
defenses against death anxiety, such as narcissistic maternal omnipotence (Leon, 1990), symbolic immortality (Firestone, 1994; Florian \& Mikulincer, 1998; Lifton, 1973), and birth's "victory of life over death" (Deutsch, 1945, p. 1), yet empirical study of the relation between fear of death and maternal grief has been meager (Tolstikova, Fleming, \& Chartier, 2005).

To cope with the fear of death, people "erect defenses against death awareness, defenses that are based on denial, that shape character structure, and that, if maladaptive, result in... psychopathology" (Yalom, 1980, p. 27). In this context, the fear of death can be considered a maladaptive personality trait with relevance to all manner of psychopathology, including generalized anxiety, anxiety conditions such as obsessive-compulsive disorder and agoraphobia, hypochondriasis, and depression (Becker, 1973; Firestone, 1994; Meyer, 1975; Neimeyer, Wittkowski, \& Moser, 2004; Pettigrew \& Dawson, 1979; Yalom, 1980). The fact that dysfunctional personality traits and mental ill health have been shown to correlate with maternal grief (Barr, 2004; Lasker \& Toedter, 2000; Robinson \& Marwit, 2006) presupposes the possibility of an important relationship between dispositional fear of death and maternal grief.

According to adult attachment theory (Mikulincer, Shaver, \& Pereg, 2003; Shaver \& Tancredy, 2001), chronic grief is more likely to afflict individuals with dysfunctional attachment styles compared with people with a secure attachment style (Archer, 1999; Bonanno \& Kaltman, 1999; Weiss, 2001). Likewise, in relation to the fear of death, Florian and Mikulincer (1998; Mikulincer \& Florian, 2000; Mikulincer, Florian, \& Tolmacz, 1990) have reported positive correlations between ambivalent and avoidant attachment styles and death salience. In relation to attachment theory, therefore, one might anticipate a significant relationship between fear of death and maternal grief.

The foregoing theoretical considerations and the lack of empirical investigation of the relation between death anxiety and grief prompted the present research, which was designed to explore the hypothesis that personal fear of death has a significant correlation with maternal grief following bereavement owing to miscarriage, stillbirth, neonatal death, or infant/child death. 


\section{Methods}

\section{Procedure}

The study was posted on the Mothers in Sympathy and Support (M.I.S.S.) Foundation website from March 2005 through August 2006. The website usually registers more than one million visits per month. The M.I.S.S. Foundation is a non-profit tax-exempt charitable organization that provides crisis and long-term support for families after the death of a child (M.I.S.S. Foundation, 2006). In addition, Foundation members and affiliates were notified of the study through Internet links, e-mail lists, and bereaved parent organizations and support groups. The study questionnaires could be completed online or downloaded and mailed on completion to the Foundation for online data entry. The data from the HTML web form were saved to a MySQL database using PHP scripting language and an Apache web server (Birnbaum, 2004).

Prospective participants were invited to take part in a study that sought to understand the relation between fear of death ("personal attitude to death") and grief ("present thoughts and feelings about your loss") following bereavement from miscarriage, stillbirth, neonatal death, or infant/child death. Participants were advised that the study was anonymous and personally identifying information was not sought. The study was considered to involve no more than minimal-risk to participants' well-being (Kraut et al., 2004), though they were informed that participation in the study might be an exacting emotional experience, albeit shortlived (Cook, 2001). Participants were invited to contact the study investigators should they have queries about the study or concerns about their personal well-being. A pledge was made to post a plain-English version of the results of the research on the M.I.S.S. Foundation website, once the study had been peer-reviewed for publication. The respondents' continued participation was considered to constitute informed consent (Kraut et al., 2004).

The participants responded first to a request for information concerning demographic variables, including gender, age, ethnicity, education, domestic living arrangement, and child bereavement history, and then they answered a series of six self-report questionnaires. The first and last of these questionnaires were 
germane to the present study and they were the Perinatal Grief Scale-33 (PGS-33; Potvin, Lasker, \& Toedter, 1989) and the Multidimensional Fear of Death Scale (MFODS; Hoelter, 1979; Neimeyer \& Moore, 1994), respectively.

\section{Participants}

The participants were recruited from the following sources: M.I.S.S. Foundation website $(n=238,59.5 \%)$, M.I.S.S. Foundation member e-mail list $(n=81,20.3 \%)$, and other $(n=81$, $20.3 \%$ ). The "other" source consisted of participants from the Foundation's support groups and other bereaved parent organizations and support groups and from the Foundation's non-member bereaved parent e-mail list. The study questionnaires were mailed to this group of participants on request and they completed the questionnaires and returned them to the Foundation for online data entry. The study was directly available online for a short period of time using Internet search engines and this may have been the point of entry for some participants.

Although 612 respondents completed the PGS-33, only 414 of these completed the MFODS and 400 of this latter group were women. The 400 women who completed both the PGS-33 and MFODS comprise the study population. The women who completed the PGS-33 and MFODS compared with women who only completed the PGS-33 were not statistically significantly different with respect to their measured grief intensity and the previously mentioned demographic variables.

The women ranged in age from 19 to 54 years $(M=32.7$, $S D=7.12)$. Their ethnicity was reported as follows: European American $(n=288,72 \%)$, African American $(n=6,1.5 \%)$, Native American (10, 2.5\%), Asian American $(n=3,0.8 \%)$, Hispanic $(n=13,3.3 \%)$, and other (non-American) $(n=80,20 \%)$. The women's reported highest level of education was as follows: Year 11 or earlier $(n=26,6.5 \%)$, high school diploma $(n=109$, $27.3 \%)$, associate degree or certificate $(n=89,22.3 \%)$, bachelor's degree $(n=112,28 \%)$, master's degree $(n=43,10.8 \%)$, and Ph.D. or advanced professional degree $(n=21,5.3 \%)$. The women's relationship status included: married or cohabiting $(n=360,90 \%)$, single $(n=14,3.5 \%)$, separated $(n=11,2.8 \%)$, and divorced $(n=15,3.8 \%)$. 
Although a history of more than one child bereavement was relatively common, the time lapse since the most recent death (TRD) was the independent variable used in the statistical analyses. The most recent category of death with the total number of child deaths for the category in parentheses was as follows: miscarriage 58 (107), stillbirth 171 (447), neonatal death 77 (146) and infant or child death 94 (187). The median TRD was 8 months (range $0-343$ months).

\section{Measures}

PERINATAL GRIEF SCALE-33 (PGS-33)

The intensity of women's grief was measured with the PGS-33 (Potvin et al., 1989), which is a short version of the Perinatal Grief Scale (PGS; Toedter, Lasker, \& Alhadeff, 1988). The PGS items were gleaned from the Expanded Texas Inventory of Grief (Zisook, Devaul, \& Click, 1982), the neonatal grief scale used by Kennell, Slyter, and Klaus (1970), and facets of grief considered unique to reproductive loss (Borg \& Lasker, 1988). The discriminant validity of the PGS has been established by confirming hypothesized correlations with variables previously known to be associated with the grief of reproductive loss, such as gestation and pre-loss mental health (Toedter et al., 1988).

The PGS-33 is a self-report questionnaire with three factor analyzed 11-item subscales referred to as Active Grief, Difficulty Coping and Despair (Toedter et al., 1988). The Active Grief subscale contains items that reflect lament over the death of a baby, such as "I cry when I think about the baby". The Difficulty Coping subscale contains items that denote social withdrawal, difficulty with normal day-to-day activities and depression, such as "I find it difficult to make decisions since the baby died". The Despair subscale contains items concerned with feelings of helplessness and hopelessness, such as "I try to laugh, but nothing seems funny anymore". The questionnaire items are presented as statements that seek responses on a 5-point Likert scale that ranges from 1 (strongly agree) to 5 (strongly disagree) with a neutral midpoint. Thirty-one of the 33 items are negatively valenced and these scores are reversed before aggregating the individual item scores to obtain the total and subscale scores such that higher scores indicate more intense grief. 
TABLE 1 Descriptive Statistics for PGS-33 Grief and MFODS

\begin{tabular}{lrcc}
\hline Measure & $M$ & $S D$ & Cronbach's $\alpha$ \\
\hline PGS-33 Grief & 110.1 & 22.92 & .94 \\
Fear of the Dying Process & $14.1(14.9)$ & $5.75(5.96)$ & .82 \\
Fear of the Dead & $17.0(19.7)$ & $5.13(5.02)$ & .68 \\
Fear of Being Destroyed & $11.5(13.8)$ & $4.48(4.74)$ & .73 \\
Fear for Significant Others & $9.9(13.6)$ & $3.48(4.95)$ & .67 \\
Fear of the Unknown & $15.3(14.9)$ & $4.89(4.11)$ & .69 \\
Fear of Conscious Death & $17.8(23.0)$ & $5.09(5.26)$ & .80 \\
Fear for the Body after Death & $21.7(24.6)$ & $5.74(4.67)$ & .78 \\
Fear of Premature Death & $9.9(12.3)$ & $3.88(4.22)$ & .73 \\
\hline
\end{tabular}

Note. $N=400$. Cronbach's $\alpha$ value for Fear of the Unknown was .88 when the item "I am afraid of meeting my creator" was omitted. PGS-33= Perinatal Grief Scale-33; MFODS $=$ Multidimensional Fear of Death Scale. The $M$ and $S D$ values in parentheses are data from Neimeyer and Moore (1994).

Women who had experienced the death of an infant or child beyond the neonatal period were included in the present study and therefore the PGS-33 was modified by replacing the word baby in the item statements with the compound word baby/ child with the permission of the scale's authors. Only the total score for PGS-33 Grief was used in the present study. The internal reliability coefficient (Cronbach's $\alpha$ ) for PGS-33 Grief was .94 (Table 1).

\section{MULTIDIMENSIONAL FEAR OF DEATH SCALE}

The intensity of the women's fear of death was measured using the MFODS (Hoelter, 1979; Neimeyer \& Moore, 1994). The validity and reliability of the MFODS has been established by testing convergent validity with other measures of death anxiety, confirming correlations with demographic variables known to be associated with death anxiety, analyzing individuals' narrative accounts of the meaning of death, evaluating internal reliability, and test-retest reliability, and performing exploratory factor analysis (Neimeyer \& Moore, 1994; Walkey, 1982).

The MFODS is a 42-item self-report questionnaire with eight factor analyzed scales representing different facets of the fear of death: Fear of the Dying Process (6 items) contains items, such 
as "I am afraid of dying very slowly"; Fear of the Dead (6 items) includes items, such as "I am afraid of things which have died"; Fear of Being Destroyed (4 items) consists of items, such as "I do not like the thought of being cremated"; Fear for Significant Others (6 items) contains items, such as "I have a fear of people in my family dying"; Fear of the Unknown (5 items) includes items, such as "I am afraid that death is the end of one's existence"; Fear of Conscious Death (5 items) comprises items, such as "I am afraid of being buried alive"; Fear for the Body after Death (6 items) consists of items, such as "The thought of my body decaying after I die scares me"; and Fear of Premature Death (4 items) contains items, such as "I am afraid I will not live long enough to experience everything I want to". Participants respond to the item statements on a 5-point Likert scale that ranges from 1 (strongly agree) to 5 (strongly disagree) with a neutral midpoint. Five of the 42 items are positively valenced and these scores are reversed prior to aggregating the individual scale items, such that lower scores indicate greater fear of death.

The Cronbach's $\alpha$ values for the eight MFODS individual scales are shown in Table 1. Three scales had Cronbach's $\alpha$ values of $<.70$ (but $>.65$ ): Fear of the Dead (.68); Fear for Significant Others (.67); and Fear of the Unknown (.69). The Cronbach's $\alpha$ value for the Fear of the Unknown scale increased to .88 when the item "I am afraid of meeting my creator" was deleted and, consequently, this item was omitted (Neimeyer \& Moore, 1994; Walkey, 1982). Item deletion did not improve the internal reliability of the other scales.

\section{Statistical Analysis}

The relative mean substitution method was used to treat the 1-2 missing values in the PGS-33 $(n=11)$ and MFODS $(n=29)$ Likert scales (Raaijmakers, 1999). The relative mean substitution method involved computing a participant's relative position in the dataset by dividing the mean of the participant's valid data by the mean of the valid data for the remainder of the participants. To estimate a missing value in an item, the previously mentioned ratio was multiplied by the mean of all of the valid data for the particular item (Raaijmakers, 1999). The TRD variable was highly positively 
skewed and therefore the values were logarithmically transformed (Log-TRD).

Exploratory factor analysis of the MFODS was performed using principal-components analysis with orthogonal (varimax) rotation and the forced extraction of eight factors. Hierarchical multiple regression analysis was performed in two blocks: LogTRD was introduced at Step 1 and the MFODS individual scales were introduced at Step 2. All statistical computations were carried out using SPSS for Windows version 14.0 (SPSS, 2005).

\section{Results}

\section{Descriptive Statistics}

The descriptive statistics for PGS-33 Grief and the eight MFODS individual scales are shown in Table 1 . The mean value for PGS33 Grief was in accord with the values reported in the literature (Toedter, Lasker, \& Janssen, 2001). Although the mean value for each MFODS individual scale was within an $S D$ of the value reported by Neimeyer and Moore (1994), the present study's participants compared with the women reported by Neimeyer and Moore (1994) had somewhat greater Fear for Significant Others, Fear of Conscious Death, and Fear of Premature Death (Table 1).

\section{Principal-Components Analysis MFODS}

A summary of the results of the MFODS factor analysis is shown in Table 2 . The factor analysis generally revealed the expected factor structure (Neimeyer \& Moore, 1994; Walkey, 1982). The eightfactor solution explained $54.7 \%$ of the variance. Seven of the eight scales loaded as predicted, though there were six significant additional loadings on other factors ( $0-2$ per scale $\geq .30$, Table 2$)$. Fear for the Body after Death (Factor 8) had a less satisfactory loading pattern because there were five additional loadings $>.30$ on Fear of Conscious Death (Factor 1, Table 2).

\section{Bivariate Correlations}

The correlation matrix for PGS-33 Grief, Log-TRD, and MFODS is shown in Table 3. There was a moderate bivariate correlation 
TABLE 2 Principal-Components Exploratory Factor Analysis MFODS

\begin{tabular}{lcccc}
\hline Measure & & & $\begin{array}{c}M \\
\text { (range) }\end{array}$ & $\begin{array}{c}\text { Additional } \\
\text { loadings (Factor) }\end{array}$ \\
\hline Fear of the Dying Process & 2 & $6 / 6$ & $.63(.52-.71)$ & $.31(1), .35(1)$ \\
Fear of the Dead & 4 & $6 / 6$ & $.58(.50-.67)$ & $.30(1), .30(8)$ \\
Fear of Being Destroyed & 5 & $4 / 4$ & $.72(.53-.84)$ & \\
Fear for Significant Others & 7 & $5 / 6$ & $.60(.34-.85)$ & $.37(2), .39(4)$ \\
Fear of the Unknown & 3 & $4 / 4$ & $.84(.74-.89)$ & \\
Fear of Conscious Death & 1 & $5 / 5$ & $.68(.52-.78)$ & \\
Fear for the Body after Death & 8 & $5 / 6$ & $.49(.31-.71)$ & $.33(2), .35(1)$, \\
& & & & $.42(1), .51(1),$. \\
Fear of Premature Death & 6 & $4 / 4$ & $.66(.43-.78)$ & $53(1), .54(1)$ \\
\hline
\end{tabular}

Note. $N=$ number of actual loadings/number of predicted loadings; Factor $=$ Factor number; $M=$ mean value for actual loadings; MFODS $=$ Multidimensional Fear of Death Scale.

between PGS-33 Grief and Log-TRD $(r=-.40)$. The correlations between PGS-33 Grief and the MFODS individual scales were mostly small $(r=-.05--.27)$. The MFODS individual scale intercorrelations were negligible to moderate $(r=.01-.48)$, except for

TABLE 3 Correlation Matrix for Regression Variables

\begin{tabular}{|c|c|c|c|c|c|c|c|c|c|c|}
\hline Measure & PGS-33 & Log-TRD & FODP & FOD & FOBD & FFSO & FOU & FCD & FFBD & FOPD \\
\hline PGS-33 & - & & & & & & & & & \\
\hline Log-TRD & $-.40^{* * *}$ & - & & & & & & & & \\
\hline FODP & $-.18^{* * *}$ & .01 & - & & & & & & & \\
\hline FOD & $-.24^{* * *}$ & $.15^{* *}$ & $.33^{* * *}$ & - & & & & & & \\
\hline FOBD & $-.17^{* * *}$ & $.10^{*}$ & $.18^{* * *}$ & $.20^{* * * *}$ & - & & & & & \\
\hline FFSO & -.05 & .09 & $.21^{* * *}$ & $.29^{* * *}$ & $.14^{* *}$ & - & & & & \\
\hline FOU & $-.20^{* * *}$ & -.07 & $.26^{* * *}$ & $.16^{* *}$ & $.10^{*}$ & .07 & - & & & \\
\hline FCD & $-.27^{* * *}$ & -.01 & $.47^{* * *}$ & $.22^{* * *}$ & $.23^{* * *}$ & -.09 & $.25^{* * *}$ & - & & \\
\hline FFBD & $-.26^{* * *}$ & .04 & $.48^{* * *}$ & $.33^{* * *}$ & $.38^{* * *}$ & .05 & $.35^{* * *}$ & $.60^{* * *}$ & - & \\
\hline FOPD & $-.22^{* * *}$ & -.01 & $.52^{* * *}$ & $.32^{* * *}$ & .01 & $.21^{* * *}$ & $.27^{* * *}$ & $.32^{* * *}$ & $.39^{* * *}$ & - \\
\hline
\end{tabular}

Note. PGS-33 = Perinatal Grief Scale-33 Grief; $\log -\mathrm{TRD}=$ Log time lapse since most recent death; FODP $=$ Fear of the Dying Process; FOD $=$ Fear of the Dead; FOBD $=$ Fear of Being Destroyed; FFSO = Fear for Significant Others; FOU = Fear of the Unknown; FCD $=$ Fear of Conscious Death; FFBD $=$ Fear for the Body after Death; FOPD $=$ Fear of Premature Death.

$$
{ }^{*} p<.05 ;{ }^{* *} p<.01 ;{ }^{* * *} p<.001 \text {. }
$$


large correlations between Fear of the Dying Process and Fear of Premature Death $(r=.52)$ and between Fear of Conscious Death and Fear for the Body after Death $(r=.60)$.

\section{Hierarchical Multiple Regression}

The result of the hierarchical multiple regression of PGS-33 Grief on Log-TRD and MFODS is shown in Table 4. The multiple $R$ value was significantly different from zero at both steps. LogTRD explained $17 \%$ of the variance in PGS-33 Grief (adjusted $\left.R^{2}=.17, p<.001\right)$. MFODS controlled for Log-TRD explained a further $12 \%$ of the variance in PGS-33 Grief $\left(\Delta R^{2}=.12\right.$, $p<.001)$. After all variables were entered in the regression, LogTRD $(\beta=-.41, p<.001)$ and three MFODS individual scales, namely Fear of the Unknown $(\beta=-.13, p<.01)$, Fear of Conscious Death $(\beta=-.17, p<.01)$ and Fear of Premature Death $(\beta=-.12, p<.05)$, made significant unique contributions to the variance in PGS-33 Grief.

A second hierarchical multiple regression omitting Fear of Conscious Death showed that the unique contribution made by

TABLE 4 Hierarchical Multiple Regression of PGS-33 Grief on MFODS

\begin{tabular}{lrrrc}
\hline Variable & B & $S E$ B & $\beta$ & $t$ \\
\hline Step 1 & & & & \\
Log-TRD & -14.55 & 1.61 & -.41 & $-9.02^{* * *}$ \\
Step 2 & -14.38 & 1.54 & -.41 & $-9.34^{* * *}$ \\
$\quad$ Log-TRD & .15 & .22 & .04 & .68 \\
Fear of the Dying Process & -.38 & .22 & -.08 & -1.76 \\
Fear of the Dead & -.29 & .24 & -.06 & -1.20 \\
Fear of Being Destroyed & .25 & .31 & .04 & .81 \\
Fear for Significant Others & -.57 & .20 & -.13 & $-2.79^{* *}$ \\
Fear of the Unknown & -.77 & .26 & -.17 & $-3.02^{* *}$ \\
Fear of Conscious Death & -.11 & .24 & -.03 & -.46 \\
Fear for the Body after Death & -.70 & .31 & -.12 & $-2.29^{*}$ \\
Fear of Premature Death & & & & \\
\hline
\end{tabular}

Note. Step 1: $R=.41 F(1,398)=81.32, p<.001, R^{2}=.17$, Adjusted $R^{2}=.17$. Step 2: $R=.54, \quad F(9, \quad 390)=18.07, \quad p<.001, \quad R^{2}=.29, \quad$ Adjusted $R^{2}=.28 . \quad \Delta R^{2}=.12$, $F$ change $=8.61, p<.001$. Log-TRD $=$ Log time lapse since most recent death. PGS-33 $=$ Perinatal Grief Scale-33. MFODS $=$ Multidimensional Fear of Death Scale.

${ }^{*} p<.05 ;{ }^{* *} p<.01 ;{ }^{* * *} p<.001$. 
Fear for the Body after Death to the variance in PGS-33 Grief approached but did not reach statistical significance $(\beta=-.10$, $t=-1.86, p=.06)$.

\section{Discussion}

The present research showed there was a significant relationship between women's fear of death and their grief following bereavement from miscarriage, stillbirth, neonatal death, or infant/child death. The particular (MFODS) fears of death that were correlated with maternal grief were fear of the unknown, fear of premature death, and fear of conscious death. These findings echo those of Feifel and Branscomb (1973) who reported that consciously experienced fear of death was described in terms of fear of the unknown and fear of premature death. Similarly, Florian and Mikulincer (1997) showed that university students who had recently experienced a "significant other" bereavement compared with those not recently bereaved exhibited more fear related to the "unknown nature of death" and "loss of self-fulfillment". Florian and Mikulincer (1997) also noted that the recently bereaved had more "fear of self-annihilation", but the present study failed to show a statistically significant relationship between (MFODS) fear for the body after death and maternal grief. However, this particular scale's factor structure was problematic because there were dual loadings on the fear of conscious death factor, which itself had a significant relationship with maternal grief. In any event, the fear of death that is operative in relation to maternal grief seems to be the existential "fear of personal extinction", which is captured by fear of the unknown and fear of premature death, rather than fears that "lie on this side of death" (Yalom, 1980, p. 43), such as fear of the dying process and fear for significant others. The side-of-death metaphor may help explain the lack of an expected correlation between fear for significant others and grief, because grieving mothers not infrequently express concern for the safety and wellbeing of their surviving children (Raphael, 1983). Alternatively, a bereaved mother's fears for her other children or her worry about their concerns for her may be thought of as rational short-lived state or mood responses to an existential reality rather than a possibly pathogenic manifestation of a personality trait based on a particular fear of death. 
The cross-sectional and correlational design of the study precludes any conclusion regarding direction of causality. Consequently, the fear of death may have been an antecedent, concomitant, and/or consequence of maternal grief. In other words, although a dispositional fear of death might have exacerbated maternal grief, it is equally possible that a mother's fear of death might have been triggered by the death of her child, or, indeed, the relationship may have been bidirectional. Alternatively, the association between fear of death and maternal grief might have been fortuitous by way of a correlation in common with an unmeasured third variable, such as a dysfunctional attachment style. Importantly, none of the PGS-33 items had fear of death specific face validity and the correlations between the PGS-33 and MFODS were small, thereby suggesting the scales measured different constructs.

The PGS-33 and MFODS are rating-scale item measures and therefore open to the usual criticisms directed at this form of data acquisition, including participant acquiescence, indecisiveness and extreme responsiveness (Rust \& Golombok, 1999; Stone et al., 2000). In addition, the study format did not control for social desirability (Baldwin, 2000) or the desire to appear psychologically healthy (Shedler, Mayman, \& Manis, 1993).

The predominantly Internet-based format of the present study permitted low-cost access to a large number of bereaved parents who could choose if, when, how much, and, to some extent, where they participated in a survey that was amenable to online research (Kraut et al., 2004; Reips, 2002). There was no attempt to avoid or control multiple submissions, though the final dataset was scrutinized for obvious duplications and none was found (Reips, 2002). The fact that only two-thirds of the respondents completed both the PGS-33 and the MFODS was evidence of a moderate drop-out rate (Reips, 2002). The unwanted presence of drop-out and the resultant commitment bias was offset by the likely minimization of shallow or mendacious responses and the reassurance that complete datasets collected online are usually accurate (Reips, 2002). Nonetheless, caution should be exercised in generalizing the results of the present study to other populations of bereaved mothers.

Despite the aforementioned methodological limitations, there was a significant correlation between dispositional fear of death 
and maternal grief. In their review of the psychotherapeutic facilitation of "normal" grieving, Raphael, Minkov, and Dobson (2001) included "expressing the various affects of grief" (p. 600). The present study suggests that personal fear of death, perhaps presenting covertly as generalized anxiety, agoraphobia, or depression, may be among the various affects of grief that needs to be expressed, understood, psychologically reframed and assimilated by bereaved mothers, though it should be noted that expressing negative affect per se may be of limited benefit or even counterproductive in bereavement counseling (Bonanno \& Kaltman, 1999).

A functionalist view of emotion would posit an adaptive function for death anxiety (Barrett \& Campos, 1987; Stolorow, 1973; Yalom, 1980). Certainly, from the purview of existential philosophy "the physicality of death destroys man, [but] the idea of death saves him" (Yalom, 1980, p. 30), because the awareness of one's mortality may encourage, even demand, self-actualization (Tomer, 1994). Although the present study did not address the adaptive value of death anxiety in maternal grief, awareness of personal finitude may be a motivating factor in some women's post bereavement commitment to a more authentic life (Kohner \& Henley, 2001, pp. 141-156; Shaver \& Tancredy, 2001; Yalom, 1980).

Before his death, Rabbi Zusya said "In the coming world, they will not ask me: 'Why were you not Moses?' They will ask me: 'Why were you not Zusya?" (Buber, 1975).

\section{References}

Archer, J. (1999). The nature of grief: The evolution and psychology of reactions to loss. London: Routledge.

Baldwin, W. (2000). Information no one else knows: The value of self-report. In A. A. Stone, J. S. Turkkan, C. A. Bachrach, J. B. Jobe, H. S. Kurtzman, \& V. S. Cain (Eds.), The science of self-report: Implications for research and practice (pp. 3-7). Mahawah, NJ: Erlbaum.

Barr, P. (2004). Guilt- and shame-proneness and the grief of perinatal bereavement. Psychology and Psychotherapy: Theory, Research and Practice, 77, 493-510.

Barrett, K. C. \& Campos, J. J. (1987). Perspectives on emotional development II: A functionalist approach to emotions. In J. D. Osofsky (Ed.), Handbook of infant development (2nd ed., pp. 555-578). Oxford, England: Wiley.

Becker, E. (1973). The denial of death. New York: Free Press.

Birnbaum, M. H. (2004). Human research and data collection via the Internet. Annual Review of Psychology, 55, 803-832. 
Bonanno, G. A. \& Kaltman, S. (1999). Toward an integrative perspective on bereavement. Psychological Bulletin, 125, 760-776.

Bonanno, G. A., Wortman, C. B., Lehman, D. R., Tweed, R. G., Haring, M., Sonnega, J. et al. (2002). Resilience to loss and chronic grief: A prospective study from preloss to 18-months postloss. Journal of Personality and Social Psychology, 83, 1150-1164.

Borg, S. \& Lasker, J. (1988). When pregnancy fails: Families coping with miscarriage, ectopic pregnancy, stillbirth, and infant death. New York: Bantam Books.

Buber, M. (1975). Tales of the Hasidim: The early masters. New York: Schocken Books.

Cook, A. S. (2001). The dynamics of ethical decision making in bereavement research. In M. S. Stroebe, R. O. Hansson, W. Stroebe, \& H. Schut (Eds.), Handbook of bereavement research: Consequences, coping, and care (pp. 119-142). Washington, DC: American Psychological Association.

Deutsch, H. (1945). The psychology of women: A psychoanalytic interpretation (Vol. 2). New York: Grune and Stratton.

Feifel, H. \& Branscomb, A. B. (1973). Who's afraid of death? Journal of Abnormal Psychology, 81, 282-288.

Firestone, R. M. (1994). Psychological defenses against death anxiety. In R. A. Neimeyer (Ed.), Death anxiety handbook: Research, instrumentation, and application (pp. 217-241). Washington, DC: Taylor \& Francis.

Florian, V. \& Mikulincer, M. (1997). Fear of personal death in adulthood: The impact of early and recent losses. Death Studies, 21, 1-24.

Florian, V. \& Mikulincer, M. (1998). Symbolic immortality and the management of the terror of death: The moderating role of attachment style. Journal of Personality and Social Psychology, 74, 725-734.

Furman, E. P. (1978). The death of a newborn: Care of the parents. Birth and the Family Journal, 5, 214-218.

Hoelter, J. W. (1979). Multidimensional treatment of fear of death. Journal of Consulting and Clinical Psychology, 47, 996-999.

Kastenbaum, R. (1974). Fertility and the fear of death. Journal of Social Issues, 30, 63-78.

Kennell, J. H., Slyter, H., \& Klaus, M. H. (1970). The mourning response of parents to the death of a newborn infant. New England Journal of Medicine, 283, 344-349.

Kohner, N. \& Henley, A. (2001). When a baby dies: The experience of late miscarriage, stillbirth and neonatal death. London, England: Routledge.

Kraut, R., Olson, J., Banaji, M., Bruckman, A., Cohen, J., \& Couper, M. (2004). Psychological research online: Report of Board of Scientific Affairs' Advisory Group on the conduct of research on the Internet. American Psychologist, 59, $105-117$.

Lasker, J. N., \& Toedter, L. J. (2000). Predicting outcomes after pregnancy loss: Results from studies using the Perinatal Grief Scale. Illness, Crisis \& Loss, 8, 350-372.

Leon, I. G. (1990). When a baby dies: Psychotherapy for pregnancy and newborn loss. New Haven, CT: Yale University Press. 
Lifton, R. J. (1973). The sense of immortality: On death and the continuity of life. American Journal of Psychoanalysis, 33, 3-15.

M.I.S.S. Foundation. (2006). http://www.missfoundation.org.

Meyer, J. E. (1975). Death and neurosis. New York: International Universities Press.

Mikulincer, M., \& Florian, V. (2000). Exploring individual differences in reactions to mortality salience: Does attachment style regulate terror management mechanisms? Journal of Personality E Social Psychology, 79, 260-273.

Mikulincer, M., Florian, V., \& Tolmacz, R. (1990). Attachment styles and fear of personal death: A case study of affect regulation. Journal of Personality and Social Psychology, 58, 273-280.

Mikulincer, M., Shaver, P. R., \& Pereg, D. (2003). Attachment theory and affect regulation: The dynamics, development, and cognitive consequences of attachment-related strategies. Motivation and Emotion, 27, 77-102.

Neimeyer, R. A., \& Moore, M. K. (1994). Validity and reliability of the Multidimensional Fear of Death Scale. In R. A. Neimeyer (Ed.), Death anxiety handbook: Research, instrumentation, and application (pp. 103-119). Washington, DC: Taylor \& Francis.

Neimeyer, R. A., Wittkowski, J., \& Moser, R. P. (2004). Psychological research on death attitudes: An overview and evaluation. Death Studies, 28, 309-340.

Pettigrew, C., \& Dawson, J. G. (1979). Death anxiety: State or trait? Journal of Clinical Psychology, 35, 154-158.

Potvin, L., Lasker, J., \& Toedter, L. (1989). Measuring grief: A short version of the Perinatal Grief Scale. Journal of Psychopathology and Behavioral Assessment, 11, $29-45$.

Raaijmakers, Q. A. W. (1999). Effectiveness of different missing data treatments in surveys with Likert-type data: Introducing the relative mean substitution approach. Educational and Psychological Measurement, 59, 725-748.

Raphael, B. (1983). The anatomy of bereavement. New York: Basic Books.

Raphael, B., Minkov, C., \& Dobson, M. (2001). Psychotherapeutic and pharmacological intervention for bereaved persons. In M. S. Stroebe, R. O. Hansson, W. Stroebe, \& H. Schut (Eds.), Handbook of bereavement research: Consequences, coping, and care (pp. 587-612). Washington, DC: American Psychological Association.

Reips, U.-D. (2002). Standards for Internet-based experimenting. Experimental Psychology, 49, 243-256.

Robinson, T., \& Marwit, S. J. (2006). An investigation of the relationship of personality, coping, and grief intensity among bereaved mothers. Death Studies, 30, 677-696.

Rust, J., \& Golombok, S. (1999). Modern psychometrics: The science of psychological assessment (2nd ed.). London: Routledge.

Shaver, P. R., \& Tancredy, C. M. (2001). Emotion, attachment, and bereavement: A conceptual commentary. In M. S. Stroebe, R. O. Hansson, W. Stroebe, \& H. Schut (Eds.), Handbook of bereavement research: Consequences, coping, and care (pp. 63-88). Washington, DC: American Psychological Association.

Shedler, J., Mayman, M., \& Manis, M. (1993). The illusion of mental health. American Psychologist, 48, 1117-1131.

SPSS. (2005). SPSS for Windows (Version 14.0). Chicago: Author. 
Stolorow, R. D. (1973). A note on death anxiety as a development achievement. American Journal of Psychoanalysis, 34, 351-353.

Stone, A. A., Turkkan, J. S., Bachrach, C. A., Jobe, J. B., Kurtzman, H. S., \& Cain, V. S. (Eds.). (2000). The science of self-report: Implications for research and practice. Mahawah, NJ: Erlbaum.

Toedter, L. J., Lasker, J. N., \& Alhadeff, J. M. (1988). The Perinatal Grief Scale: Development and initial validation. American Journal of Orthopsychiatry, 58, 435-449.

Toedter, L. J., Lasker, J. N., \& Janssen, H. J. (2001). International comparison of studies using the Perinatal Grief Scale: A decade of research on pregnancy loss. Death Studies, 25, 205-228.

Tolstikova, K., Fleming, S., \& Chartier, B. (2005). Grief, complicated grief, and trauma: The role of the search for meaning, impaired self-reference, and death anxiety. Illness, Crisis, \& Loss, 13, 293-313.

Tomer, A. (1994). Death anxiety in adult life-theoretical perspectives. In R. A. Neimeyer (Ed.), Death anxiety handbook: Research, instrumentation, and application (pp. 3-28). Washington, DC: Taylor \& Francis.

Walkey, F. H. (1982). The Multidimensional Fear of Death Scale: An independent analysis. Journal of Consulting and Clinical Psychology, 50, 466-467.

Weiss, R. S. (2001). Grief, bonds, and relationships. In M. S. Stroebe, R. O. Hansson, W. Stroebe \& H. Schut (Eds.), Handbook of bereavement research: Consequences, coping, and care (pp. 47-62). Washington, DC: American Psychological sAssociation.

Yalom, I. D. (1980). Existential psychotherapy. New York: Basic Books.

Zisook, S., Devaul, R. A., \& Click, M. A., Jr. (1982). Measuring symptoms of grief and bereavement. American Journal of Psychiatry, 139, 1590-1593. 
Copyright of Death Studies is the property of Routledge and its content may not be copied or emailed to multiple sites or posted to a listserv without the copyright holder's express written permission. However, users may print, download, or email articles for individual use. 